\title{
PRODUKSI IKAN UNGGUL DI LAHAN MINAPADI SECARA INTENSIF
}

\author{
Wahyulia Cahyanti*, Vitas Atmadi Prakoso, Otong Zenal Arifin,dan Irin Iriana Kusmini \\ Balai Penelitian dan Pengembangan Budidaya Air Tawar \\ "e-mail : wahyulia_kkp@yahoo.com
}

\section{ABSTRACT \\ Superior Fish Production in Intensive Paddy Cum Fish Culture}

\begin{abstract}
Aquaculture development in Indonesia is expected to push forward the fish farmers entrepreneurship and competitiveness of aquaculture products in a sustainable manner through improved efficiency and cooperative advantages. Development of fisheries resources in accordance with the management and the optimal use or to provide added value of the fish itself also to provide other products. One technology that can be used is through technology in paddy cum fish culture. This study aimed to improve of land productivity through superior tilapia production in paddy cum fish culture system. In general, the best results obtained in treatment A (no treatment). Productivity of rice and fish could be enhanced by applying paddy cum fish culture system by 4 to 5.5 million or 10-15\% per hectare rice field.
\end{abstract}

Keywords: Minapadi, Productivity, Nila, Fertilizer

\begin{abstract}
ABSTRAK
Pengembangan perikanan budidaya di Indonesia ke depan diharapkan dapat mendorong masyarakat perikanan/pembudidaya untuk meningkatkan jiwa kewirausahaan dan daya saing produk perikanan budidaya secara berkelanjutan melalui peningkatan efisiensi dan keunggulan koperatif. Pengembangan sumber daya perikanan yang sesuai dengan pengelolaan dan pemanfaatan yang optimal dan dapat memberikan nilai tambah selain dari ikannya itu sendiri juga produk lainnya. Salah satu teknologi yang dapat digunakan yaitu melalui teknologi minapadi. Penelitian ini bertujuan untukmeningkatkan produktivitas lahan melalui produksi ikan nila unggul dalam sistem minapadi. secara umum, hasil terbaik diperoleh pada perlakuan A (tanpa perlakuan). Dari hasil penelitian, didapatkan kesimpulan bahwa Ikan nila lebih baik pertumbuhannya dibanding mas.Secara umum hasil terbaik diperoleh dari lahan kontrol atau tanpa perlakuan. Produktivitas padi dan ikan dapat ditingkatkan dengan menerapkan sistem minapadi senilai 4-5,5 juta atau 10-15\% tiap hektar sawah.
\end{abstract}

Kata kunci : minapadi, produktifitas, Nila, pupuk

\section{PENDAHULUAN}

Perikanan budidaya merupakan sektor penyedia sumber makanan yang sangat cepat perkembangannya. Saat ini, sektor budidaya hampir memberikan kontribusi sekitar $50 \%$ dari total produksi perikanan dunia, dan sektor ini akan tetap menjadi tumpuan penyedia sumber makanan bagi perkembangan kebutuhan makanan di masa depan (FAO Fisheries Departement, 2006). Produksi perikanan budidaya di Indonesia sangat menjanjikan, hal ini terbukti dengan masuknya Indonesia sebagai salah satu penghasil produksi perikanan budidaya di dunia (FAO Fisheries Departement, 2006).
Salah satu produksi perikanan budidaya di Indonesia dihasilkan dari sistem minapadi.Budidaya minapadi adalah budidaya terpadu yang meningkatkan produktivitas lahan sawah yang menghasilkan padi dan juga ikan. Budidaya minapadi juga merupakan solusi terbaik dalam menghadapi perubahan iklim yang ekstrim seperti saat ini. Sebagian besar ikan yang dibudidayakan dengan metode budidaya ini adalah ikan mas dan ikan nila walaupun sebenarnya tidak hanya dua komoditas tersebut yang dapat dibudidayakan dengan metode ini. Komoditas lain yang dapat dibudidayakan dengan metode ini antara lain nilem, tawes dan udang galah. 
Biasanya budidaya ikan pada sistem minapadi mengandalkan tumbuhnya pakan alami yang dihasilkan dari proses pemupukan. Ikan yang dipelihara tidak diberi pakan tambahan apapun dan dipelihara secara tradisional.Walaupun menurut Ali dan Mateo (2007), pada sistem minapadimenunjukkan bahwa integrasi ikan dan padi memiliki manfaat ekonomi lebih tinggi daripada monokultur padi konvensional, namun hasil tersebut masih belum bisa maksimal.

Budidaya secara intensif menjadi salah satu cara yang dapat dilakukan dalam rangka peningkatan produksi ikan. Pada lahan minapadi ini, yang dapat dilakukan adalah budidaya ikan secara intensif dengan pemberian pakan dan pupuk tambahan untuk memacu pertumbuhan ikan.Oleh karena itu dilakukan penelitian ini, agar diketahui pengaruh pemberian pakan terhadap pertumbuhan ikan di lahan minapadi.

\section{BAHAN DAN METODE}

Kegiatan ini dilaksanakan di lahan sawah masyarakat di Bogor (dengan luasan $90 \mathrm{~m}^{2} /$ petak) Lama pemeliharaan ikan selama 45 hari. Terdiri dari 4 perlakuan dengan 3 kali ulangan, masingmasing perlakuan sebagai A (Tanpa perlakuan), B (Diberi tambahan pakan), C (Diberi tambahan pupuk) dan D (Diberi tambahan pakan dan pupuk). Tahapan kegiatan penelitian adalah sebagai berikut;

\section{a. Penanaman Padi}

Varietas padi yang digunakan sesuai dengan varietas yang dikembangkan di lokasi penelitianpadi Super, Cijeruk. Pola tanam minapadi yang digunakan adalah metode tumpangsari dengan pola tanamCaren Keliling, yaitu dengan membuat caren keliling sawah dengan lebar $1 \mathrm{~m}$ dan kedalaman 30-40 $\mathrm{cm}$.

\section{b. Penebaran Ikan}

Ikan yang digunakan adalah ikan nila BEST dengan ukuran 1-1,5 cm dan ikan mas dengan ukuran 2-2,5 cm. Penggunaan ukuran ikan yang berbeda adalah untuk menghindaripemangsaan ikan mas oleh ikan nila. Jumlah benih ikan sebanyak 10 ekor/m $\mathrm{m}^{2}$ sawah. Ikan ditebar pada saat tanaman padi berumur 10-15 HST (setelah penyiangan pertama dan pemupukan dasar).

\section{c. Pemupukan}

Pemupukan dilakukan dua kali yaitu, pemupukan dasar dengan menggunakanPupuk organik : 0,1-0,2 $\mathrm{kg} / \mathrm{m}^{2}$ sebagai pupuk dasar diberikan sesudah pengolahan tanah dan pemupukan Urea $(200 \mathrm{~kg} / \mathrm{Ha}), \quad$ SP $36 \quad(100 \mathrm{~kg} / \mathrm{Ha})$. Pemupukan Susulan dlakukan setelah 2 minggu dari pemupukan pertama menggunakan urea dengan dosis $50 \mathrm{~kg} / \mathrm{Ha}$. Setelah ikan berumur 2-3 minggu, pupuk organik kembali $0,1-0,2 \mathrm{~kg} / \mathrm{m}^{2}$ diberikan dengan cara ditebar.

\section{d. Pemeliharaan Ikan}

Selama pemeliharaan, ikan diberi pakan komersial dengan kadar protein $28-32 \%$, diberikan sebanyak $3 \%$ per hari dari bobot biomasa dengan 2 kali pemberian per hari (pagi dan sore hari)

\section{e. Pengukuran Kualitas Air}

Kualitas air yang diukur meliputi DO (Dissolved Oxygen), suhu, pH, amoniak $\left(\mathrm{NH}_{3}\right)$, Pospat, Alkalinitas, Kesadahan, dan $\mathrm{CO}_{2}$. Keseluruhan parameter kualitas air tersebut diambil diawal pemeliharaan, ditengah pemeliharaan, dan diakhir pemeliharaan.

\section{f. Parameter Penelitian}

Pengamatan ini dilakukan setiapdua minggu sekali. Koleksi data pertumbuhan dilakukan dengan cara mengukur panjang standar dan bobot, serta sintasan ikan pada akhir penelitian. 
Analisa data menggunakan multivariate analysis of variance (MANOVA) dan dlanjutkan dengan Tukey HSD tes pada program STATISTICA V.6 untuk menguji tingkat perbedaan yang ada.

\section{Pertumbuhan Mutlak}

Perhitungan pertambahan biomas dan laju pertambahan panjang bulanan menggunakan rumus sebagai berikut (Matricia et al., 1989):

$$
\mathrm{W}=\mathrm{Wt}-\mathrm{Wo}_{\mathrm{o}}
$$

$\mathrm{W}=$ Pertumbuhan mutlak

$\mathrm{Wt}=$ Rataan pertumbuhan mutlak pada hari ke-

$\mathrm{Wo}_{\mathrm{o}}$ Rataan pertumbuhan mutlak pada awal penelitian

\section{Laju Pertumbuhan Spesifik}

$$
S G R=\frac{(\ln W t-\ln W o)}{t} \times 100 \%
$$

Keterangan :

$\mathrm{SGR}=$ Laju pertumbuhan spesifik (\%bt/Hari)

$\mathrm{Wt}=$ Berat ikan pada akhir penelitian (g)

$\mathrm{Wo}=$ Berat ikan pada awal penelitian (g)

$\mathrm{t}=$ Waktu penelitian (hari)

\section{Sintasan}

$$
\mathrm{SR}=\frac{\mathrm{Nt}}{\mathrm{No}} \times 100 \%
$$

Keterangan :

$\mathrm{SR}=$ Sintasan $(\%)$

$\mathrm{Nt}=$ Jumlah populasi pada akhir penelitian (ekor)

No $=$ Jumlah populasi pada awal penelitian (ekor)

\section{HASIL DAN PEMBAHASAN}

\section{Pertumbuhan}

Hasil pengamatan menunjukan bahwa ikan nila dan mas mampu beradaptasi terhadap lingkungan minapadi sebagai komoditas yang digunakan. Tabel 1 menunjukkan pertambahan bobot dan panjang ikan nila BEST maupun mas dengan ukuran penebaran awal sebesar $1-1,5 \mathrm{~cm}$ selama 45 hari masa pemeliharaan. Pertambahan bobot tertinggi sebesar $3,27 \pm 0,79 \mathrm{~g}$ (untuk ikan nila), 2,80 $\pm 0,74 \mathrm{~g}$ (untuk ikan mas) dan panjang $3,42 \pm 0,17 \mathrm{~cm}$ (untuk ikan nila), 2,29 $\pm 0,23 \mathrm{~cm}$ (untuk ikan

\begin{tabular}{|c|c|c|c|c|c|c|c|c|}
\hline \multirow{2}{*}{$\begin{array}{l}\text { Perlakuan } \\
\text { Parameter }\end{array}$} & \multicolumn{2}{|c|}{ A } & \multicolumn{2}{|c|}{ B } & \multicolumn{2}{|c|}{$\mathrm{C}$} & \multicolumn{2}{|c|}{$\mathrm{D}$} \\
\hline & Nila & Mas & Nila & Mas & Nila & Mas & Nila & Mas \\
\hline $\begin{array}{l}\text { Panjang mutlak } \\
(\mathrm{cm})\end{array}$ & $\begin{array}{c}2,35 \pm \\
0,34\end{array}$ & $\begin{array}{c}1,61 \pm \\
0,32\end{array}$ & $\begin{array}{c}3,09 \pm \\
0,31\end{array}$ & $\begin{array}{c}2,29 \pm \\
0,23\end{array}$ & $\begin{array}{c}3,42 \pm \\
0,17\end{array}$ & $\begin{array}{c}2,16 \pm \\
0,40\end{array}$ & $\begin{array}{c}3,34 \pm \\
0,33\end{array}$ & $\begin{array}{c}2,13 \pm \\
0,50\end{array}$ \\
\hline $\begin{array}{l}\text { Bobot mutlak } \\
\text { (gram) }\end{array}$ & $\begin{array}{c}1,66 \pm \\
0,55\end{array}$ & $\begin{array}{c}0,98 \pm \\
0,53\end{array}$ & $\begin{array}{c}2,55 \pm \\
0,53\end{array}$ & $\begin{array}{c}1,74 \pm \\
0,26\end{array}$ & $\begin{array}{c}3,27 \pm \\
0,79\end{array}$ & $\begin{array}{c}1,66 \pm \\
0,71\end{array}$ & $\begin{array}{c}2,80 \pm \\
0,74\end{array}$ & $\begin{array}{c}1,67 \pm \\
1,07\end{array}$ \\
\hline $\begin{array}{l}\text { Laju } \\
\text { pertumbuhan } \\
\text { spesifik (\%) }\end{array}$ & $\begin{array}{c}8,88 \\
\pm 1,32\end{array}$ & $\begin{array}{c}5,81 \pm \\
1,47\end{array}$ & $\begin{array}{c}9,92 \pm \\
0,23\end{array}$ & $\begin{array}{c}7,80 \pm \\
0,94\end{array}$ & $\begin{array}{c}11,72 \pm \\
0,24\end{array}$ & $\begin{array}{c}7,11 \pm \\
1,08\end{array}$ & $\begin{array}{c}11,01 \pm \\
0,62\end{array}$ & $\begin{array}{c}7,21 \pm \\
1,31\end{array}$ \\
\hline
\end{tabular}
mas).

Tabel 1. Hasil Pengukuran Ikan pada Sistem Minapadi di Cijeruk 
Faktor yang berperan disini adalah kemampuan ikan tersebut dalam beradaptasi terhadap lingkungan yang baru dan kemampuan dalam me-manfaatkan pakan alami yang terdapat di sawah serta pakan tambahan yang diberikan, sehingga mempengaruhi tingkat pertumbuhannya. Ikan nila mempunyai laju pertumbuhan yang lebih baik dibanding ikan mas, Hal tersebut diduga karena nila cenderung memakan pellet sebagai makanan utama, mengakibatkan jumlah kotoran yang juga banyak. Adanya sisa metabolisme nila tersebut meningkatkan jumlah plankton dan detritus yang lebih disukai oleh Ciprinid (mas). Sementara pada mas tidak terlalu memanfaatkan pellet yang diberikan. mas lebih menyukai lumut yang ada di tepian sawah dan pakan alami lainnya. Adapun grafik pertambahan panjang dan bobot nila, mas disajikan dengan grafik-grafik dibawah ini :

Romana-Equia \& Doyle (1992) menekankan bahwa interaksi antara lingkungan dan strain pada ikan nila sangat berperanan dalam keragaan pertumbuhan. Pertambahan panjang dan bobot yang relatif signifikan tersebut diharapkan dapat memberikan nilai tambah penghasilan bagi petani dan pembudidaya.

Hasil panen ikan nila dan mas yang ada di petani masing-masing dikumpulkan dan kemudian dipelihara sampai mencapai ukuran konsumsi. Pertambahan panjang dan bobot yang relatif signifikan tersebut diharapkan dapat memberikan nilai tambah penghasilan bagi petani dan pembudidaya.

\section{GRAFIK PANJANG NILA}

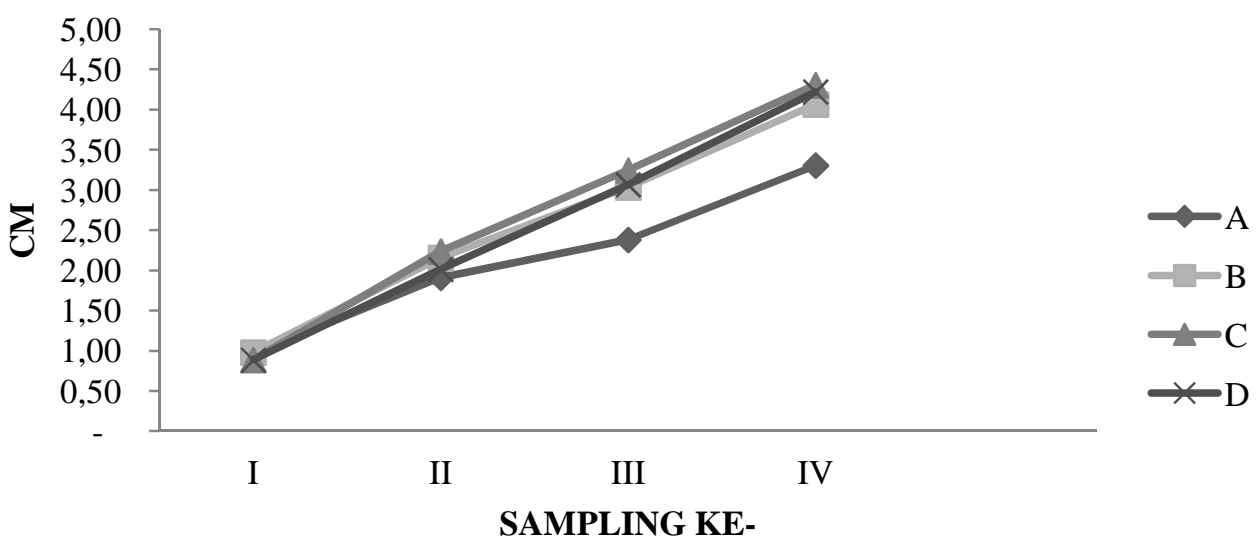

GRAFIK PANJANG MAS

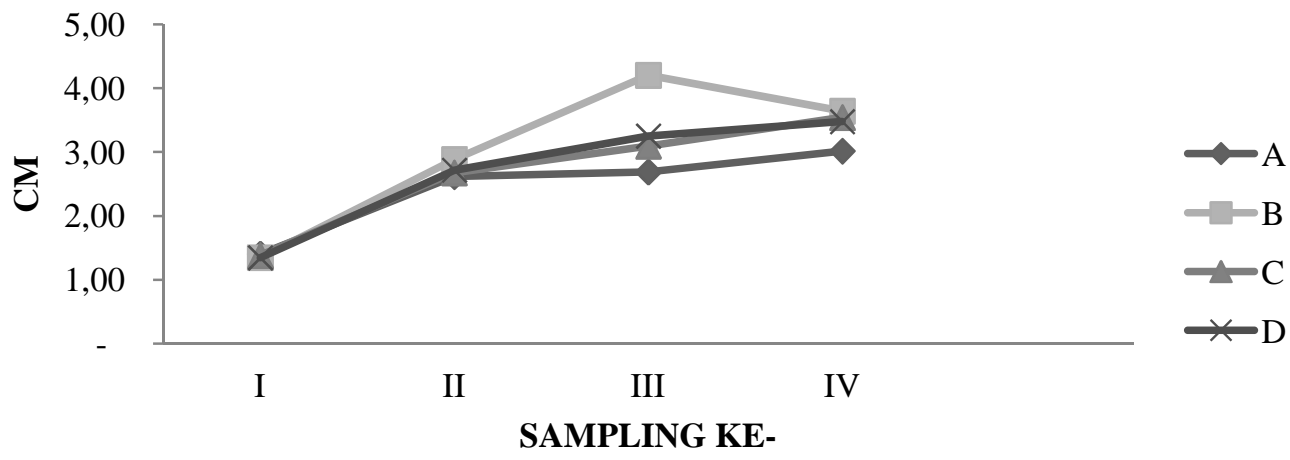

Gambar 1. Grafik Pertambahan Panjang Ikan 


\section{GRAFIK BOBOT NILA}

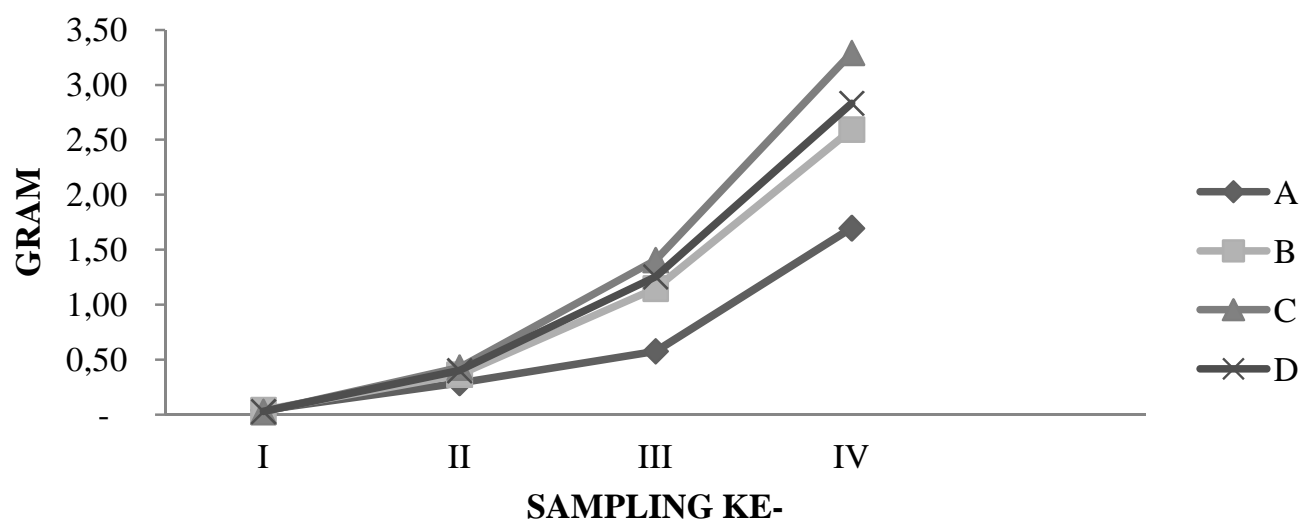

GRAFIK BOBOT MAS

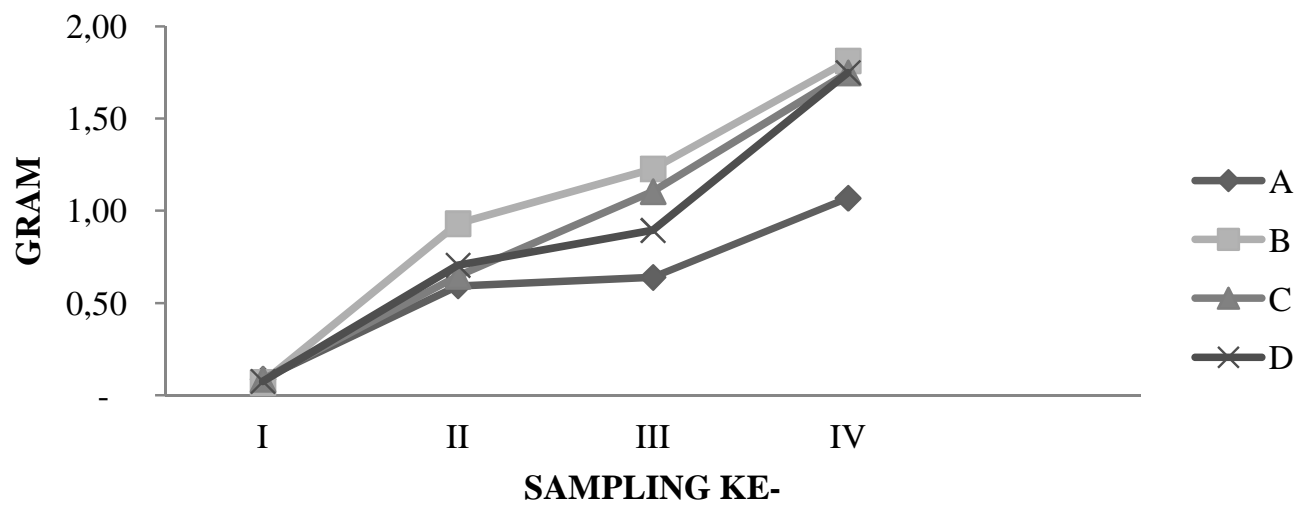

Gambar 2. Grafik Pertambahan Bobot Ikan

\section{Analisa Ekonomi}

\section{Produksi Padi}

Setelah panen ikan (45 hari pemeliharaan ikan) padi tetap dipelihara sampai 100 hari.Pada umur padi 60 hari (45 hari pemeliharaan ikan) dilakukan perlakuan pemupukan susulan. Produksi dan harga penjualan gabah kering setelah 100 hari pemeliharaan padi dengan harga gabah $\mathrm{Rp} 3.400,-/ \mathrm{kg}$. Produksi gabah tertinggi diperoleh data sama antar perlakuan yaitu $(112,5 \pm 0,57 \mathrm{~kg})$ setara dengan $4.166 \mathrm{~kg} / \mathrm{Ha}$. Produksi padi di lahan yang sama tanpa minapadi sekitar $5.000 \mathrm{~kg} / \mathrm{Ha}$ (wawancara petani). Hal ini menunjukkan bahwa dengan sistim minapadi terjadi penurunan produksi padi.Menurut Ali dan Mateo (2007), pada sistem mina padi total hasil padi per petak tanah menurun karena 10 $\%$ lahan digunakan untuk pembuatan kolam, meskipun begitu analisis ekonomi menunjukkan bahwa integrasi ikan di sistem mina padi memi-liki manfaat ekonomi lebih tinggi daripada monokultur padi konvensional.

\section{Produksi Ikan}

Hasil pengamatan menunjukkan nilai sintasan yang berbeda antara ikan nila dan ikan mas, dengan pola yang tidak jauh berbeda. Hasil terbaik untuk ikan nila ada pada perlakuan A $(21,56 \%)$ sedang untuk mas juga terdapat pada perlakuan A $(11,36 \%)$. Hal tersebut 
diduga akibat adanya keterbatasan daya dukung perairan media ikan yang merupakan perairan tergenang. Kondisi Lingkungan yg kerap kali diguyur hujan secara tiba-tiba juga akan mengguncang kondisi air. Fluktuasi tersebut lebih berpengaruh pada perlakuan $\mathrm{B}, \mathrm{C}$ dan $\mathrm{D}$ yang semakin intensif (Gambar 3).Hasil tersebut diduga akibat penggunaan pakan dan pupuk berlebih sehingga menurunkan daya dukung air sebagai media hidup ikan nila dan mas.

Nilai tersebut diatas, menggambarkan bahwa ikan nila dan mas strain unggul dapat diproduksi pada lahan minapadi. Meskipun hasilnya lebih kecil daripada pemeliharaan di kolam, namun bisa menjadi alternatif lahan untuk produksi ikan-ikan unggul.

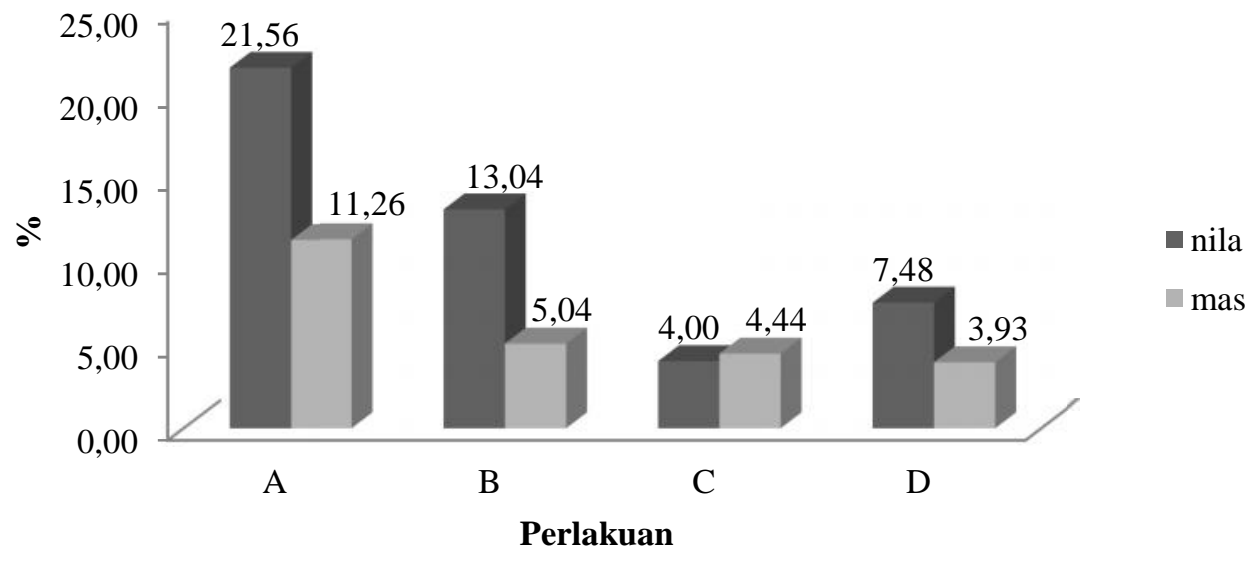

Gambar2. Grafik Tingkat Kelulushidupan

Tabel 3. Perbandingan Hasil Pendapatan Panen Sawah dengan Sistem Minapadi dan Tanpa Minapadi

\begin{tabular}{|c|c|c|c|c|c|c|c|c|c|c|}
\hline \multirow[t]{2}{*}{$\begin{array}{c}\text { Sistem } \\
\text { Budiday } \\
\text { a }\end{array}$} & $\begin{array}{c}\text { Pan } \\
\text { en } \\
\text { Gab } \\
\text { ah } \\
(\mathrm{kg} / \\
\mathrm{Ha})\end{array}$ & $\begin{array}{c}\text { Har } \\
\text { ga } \\
\text { Gab } \\
\text { ah } \\
(\mathrm{Rp} / \\
\mathrm{kg})\end{array}$ & $\begin{array}{c}\text { Nilai } \\
\text { Tamba } \\
\mathrm{h} \\
\text { (dihitun } \\
\text { g dari } \\
\text { rata- } \\
\text { rata } \\
\text { SR } \\
\text { total) }\end{array}$ & $\begin{array}{c}\text { Pendapa } \\
\text { tan } \\
\text { Gabah } \\
(\mathrm{Rp} / \mathrm{Ha})\end{array}$ & $\begin{array}{l}\text { Pendapatar } \\
\text { kan(Rp/Ha }\end{array}$ & $\begin{array}{c}\text { Pengelua } \\
\text { ran } \\
(\mathrm{Rp} / \mathrm{Ha})\end{array}$ & $\begin{array}{l}\text { Pendapata } \\
\text { n Bersih } \\
(\mathrm{Rp} / \mathrm{Ha})\end{array}$ & $\begin{array}{c}\text { Produktivita } \\
\text { s } \\
\text { (Rp/Ha/thn) }\end{array}$ & $\begin{array}{l}\text { Peningkat } \\
\text { an } \\
\text { pendapat } \\
\text { an (\%) }\end{array}$ & $\begin{array}{c}\text { Sistem } \\
\text { Budida } \\
\text { ya }\end{array}$ \\
\hline & & & $\begin{array}{l}\text { Panen } \\
\text { Ikan } \\
\text { (ekor/H } \\
\text { a) }\end{array}$ & $\begin{array}{c}\text { Harga } \\
\text { Ikan } \\
\text { (Rp/ekor } \\
\text { ) }\end{array}$ & & & & & & \\
\hline $\begin{array}{l}\overline{\text { Tanpa }} \\
\text { Minapad } \\
\text { i }\end{array}$ & 5000 & $3400,-$ & - & 1 & $\begin{array}{c}17.000 .000 \\
-\end{array}$ & - & $\begin{array}{c}3.000 .00 \\
0,-\end{array}$ & $\begin{array}{c}14.000 .0 \\
00,-\end{array}$ & $\begin{array}{c}42.000 .00 \\
0,-\end{array}$ & - \\
\hline $\begin{array}{l}\text { Minapad } \\
\mathrm{i}\end{array}$ & 4166 & $3400,-$ & 26.528 & $250,-$ & 14.164 .400 & $\begin{array}{c}6.632 .0 \\
00,-\end{array}$ & $\begin{array}{c}5.000 .00 \\
0,-\end{array}$ & $\begin{array}{c}15.796 .4 \\
00,-\end{array}$ & $\begin{array}{c}47.389 .20 \\
0,-\end{array}$ & 12 \\
\hline
\end{tabular}

Keterangan : Nilai berdasar harga pada tahun 2012 


\section{Analisa Ekonomi Minapadi}

Indikator keberhasilan yang bisa dilihat adalah adanya peningkatan pendapatan per $\mathrm{Ha}$ (hektare) dengan diterapkannya sistem minapadi dengan komoditas ikan nila dan mas di dalamnya. Dari hasil kegiatan yang dilakukan, dengan dilakukannya sistem minapadi jumlah padi pada saat dipanen mengalami pengurangan jumlah relatif kecil akibat terdapat pengurangan jumlah lahan yang digunakan untuk memelihara ikan nila, meskipun demikian, dapat disimpulkan bahwa produktivitas lahan dapat ditingkatkan dengan menerapkan sistem minapadi. Penerapan sistem minapadi dilakukan dengan harapan adanya ikan berfungsi untuk menyuburkan lahan melalui kotoran ikan yang membantu percepatan perbaikan lingkungan karena dengan pola minapadi akan mengurangi gas metan yang dibuang dari sisa pemupukan. Selain dari padi yang dihasilkan, petani juga dapat memperoleh keuntungan dari hasil memelihara ikan.

Perbandingan antara sistem minapadi dan tanpa minapadi, terdapat perbedaan hasil panen yang dihasilkan oleh petani dari ikan (nila dan mas). Dengan teknologi yang tepat, minapadi memang dapat memberi pendapatan yang cukup tinggi. Keuntungan yang didapat dari usaha tani minapadi berupa peningkatan produksi padi dan ikan, mengurangi penggunaan pestisida, pupuk anorganik, penyiangan dan pengolahan tanah (Suriapermana, et al., 1994). Perbandingan hasil pendapatan panen sawah dengan sistem minapadi dan tanpa minapadi bisa dilihat pada tabel 3.Selain itu, minapadi dapat menjadi solusi paling baik dalam menghadapi perubahan iklim yang ekstrim seperti saat ini. Sebab, teknik budidaya minapadi terdiri dari dua metode yang bisa dilakukan sekaligus dalam satu musim tanam, yaitu metode penyelang dan tumpang sari.

\section{KESIMPULAN}

Dari hasil penelitian, didapatkan kesimpulan bahwa Ikan nila lebih baik pertumbuhannya dibanding mas.Secara umum hasil terbaik diperoleh dari lahan kontrol atau tanpa perlakuan.Meskipun hasilnya lebih kecil daripada pemeliharaan di kolam, namun minapasi bisa menjadi alternatif lahan untuk produksi ikan-ikan unggul.Produktivitas padi dan ikan dapat ditingkatkan dengan menerapkan sistem minapadi senilai $12 \%$ tiap hektar sawah.

\section{DAFTAR PUSTAKA}

Ali,M.H., G.L. Mateo. 2007. Economics of Rice-Fish Culture in Wet Land Rice Ecosystems. SAARC Journal of Agriculture 5(2)

Arifin, O Z., G H. Huwoyon dan R. Gustiano. 2009. Keragaan Pertumbuhan Ikan Nila Hitam (BEST) Dan Nila Merah (NIFI) (Oreochromis niloticus) Dalam Pemeliharaan Terpisah Di Kolam. Prosiding Seminar Nasional Perikanan UGM 2009. Yogjakarta. 8 hal.

FAO Fisheries Department, 2006.State of world aquaculture 2006.FAO Fisheries Technical Paper.No. 500.Rome, 134p.

Huwoyon, G.H., O.Z. Arifin dan R. Gustiano. 2009. Uji Ketahanan Lingkungan Populasi Ikan Nila (Oreochromis niloticus) Di Karamba Jaring Apung Di Danau Lido. Prosiding Seminar Nasional Perikanan UGM 2009 Yogjakarta. 6 hal.

Matricia, T., A.J. Talbot and R.W. Doyle. $1989 . \quad$ Instantaneous Growth Rate of Tilapia Genotypes in Undisturbed Aquaculture Systems I. "Red" and "Grey" Morphs in Indonesia.Aquaculture 77: 295-302. 
Romana-Equia, M.R.R and R.W. Doyle. 1992. Genotype-Environment Interaction in the Response of Three Strains of Nile Tilapia to Poor Nutrition. Aquaculture 108:1-12.
Sugiyama, S., Staples, D., Funge-Smith, S.J., 2004. Status and potential of fisheries and aquaculture in Asia and the Pacific.FAO Regional Office for Asia and the Pacific. RAP Publication 2004/25. 53 pp. 